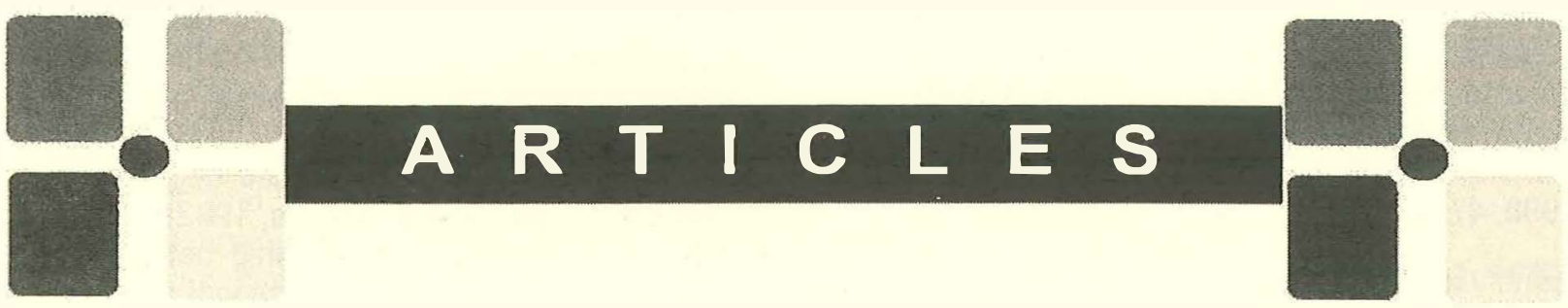

\title{
The Relationship Between Students' Computer Competency and Per- ception of Enjoyment and Difficulty Level in Web-based Distance Learning
}

\author{
By Yunfei Du, Wayne State University
}

\begin{abstract}
This paper discussed the concept of computer competency and investigated the relationship between students' computer competency and their perception of enjoyment and difficulty level of web-based distance-learning courses. Participants were 237 entering graduate students in library and information science from a mid-southwestern state university in the United States from year 2001 to 2003. Computer competency was estimated by students' self-report of their prior knowledge of information technology skills in a survey called Computer Skill and Use Assessment. Statistical significance was found between the correlation of computer competency and students' perception of enjoyment level $(p=.011)$ and difficulty level $(p=.001)$.
\end{abstract}

\section{Introduction}

Distance education has become an integral component of services from libraries, including academic libraries that serve college of education. In recent years, library and information science fields have been exploring innovative ways of teaching and learning in digital era. For example, since the 1990s, distance learning in library and information science education has developed quickly in the United States. Distance education via the World Wide Web, often combined with on-site meeting requirements, has been a trend in library and information science fields (Association for Library and Information Science Education, 1999, 7). The 2003 Association for Library and Information Science Education Statistical Report shows forty-six out of fiftysix ALA-accredited library schools reported 1,155 courses offered as distance education, in comparison to 1,008 courses in 2001,489 courses in 2000, and 408 courses in 1999 (Association for Library and Information Science Education, 2003).

While LIS practitioners and researchers are offering instruction in different formats to provide students with more flexibility, they realize the potential challenge of learning from a distance. For example, the instructor needs sufficient instructional and technical support in a sametime/different-place learning environment (Besser, 1996, 819). Many of the library educators choose different-time/different-place models to deliver courses over the Internet to reduce cost and eliminate technical challenges by twoway video-conferencing (lighting, sound, and wiring of classrooms, et al).

In asynchronous models, students can control the pace of instruction but students' individual intellectual and technical background will impact learning effectiveness. An onsite environment makes it possible for instructors to adjust teaching strategies according to student feedback via eye-contact. Learners can think, watch, observe, and participate while communicating with the instructor and classmates. In web-based learning environments, students without adequate technological background may spend more time struggling with technology than working on course content. Computer competency, or information technology literacy, may influence students' satisfaction with their performance 
within an individual course and with their general experience of web-based learning in general. Thus, chances of dropping out may increase for those students dissatisfied with their distance learning experience (Sherry, Fulford, \& Zhang, 1998, 4).

Identifying factors impacting distance learning is more valuable to education libraries because their students will be next generation of educators, who would explore pedagogical innovations at the rest of their life. The current study looked particularly at students at a library and information science program. Many of them were school librarians. This study explored how students' computer competency can impact their perception of enjoyment and difficulty level in webbased distance learning.

Distance learning was defined in this study as the application of telecommunications and electronic devices that enable learners to receive instructions originating from some distant location (Keegan, 1988; Holmberg, 1995, 51). Instruction may be synchronous or asynchronous. Distance education may employ correspondence study, or audio, video, or computer technologies.

\section{Previous Studies}

There are abundant research studies measuring student satisfaction. Students' attitudes, especially their satisfaction with online courses, are important indicators of student success. Studies show a direct relation between dissatisfaction of distance learning and student retention. Librarians and educators have been exploring factors that enhance students' satisfaction in web-based distance learning: learning styles, technology support, and learning community, et al. (Simpson \& Du, 2004; Frey, Alman, Barron, \& Steffens, 2004). Previous studies reveal a possibility of effects of learning styles and individual ability in web-based distance learning (Du, 2004).

One of the ability factors is students' prior knowledge and skills of computers. There is abundant research on the effects of specific knowledge and skills, such as prior knowledge of computers, in distance learning. Prior knowledge is defined as the knowledge, skills, or ability that students bring to the learning process (Jonassen \& Grabowski, 1993). Prior knowledge is one of the strongest and most consistent predictors of learning. Tobias states that prior knowledge can knowledge can be tested via a pretest developed specifically for a content domain. Tests can be multiple choices, free recall, true/false, or matching among others. Some tests include a scale for learner to indicate their degree of confidence in their answer (Tobias, 1982). Research suggests an inverse relationship between level of prior knowledge and instructional support. As the level of prior knowledge rises, the need for instructional support decreases; conversely, as the level of prior knowledge decreases, the need for instructional support rises (Tobias 1976, 1981; Jonassen \& Grabowski, 1993).

Theoretical backgrounds related to the importance of prior knowledge are transfer of learning, schema theory, information-processing theory, and theory of structural knowledge. Transfer of learning theory explains how prior skills and knowledge transfer directly to new learning. Schema theory explains the acquisition of new information through a learner's active, constructive integration of new information into existing networks of knowledge. Information-processing theory focuses on the roles of perception and attention in learning and memory (Jonassen \& Grabowski, 1993, 421). Structural knowledge describes and facilitates the application of pricr knowledge to novel situations. It is the knowledge of how ideas within a domain are interre. lated. In other words, structural knowledye de. scribes how prior knowledge is interconnected (Diekhoff, 1983). Structural knowledge is als defined as conceptual knowledge, the conceptual storage of meaningful dimensions in a given domain of knowledge.

In the library and information science world, a more relevant concept is probably "compute! competency", or "information technology literacy". Simonson, Maurer, Montag-Toradi, \& Whitaker (1987) define computer literacy as (1) an understanding of computer characteristics, capabilities, and applications; and (2) an ability to implement this knowledge in the skillful, productive use of computer applications. Specifically, Osika \& Sharp (2002) identified technical competencies for distance learning students as seven skill groups: (1) computer operations and utilities, (2) file management, (3) word processing, (4) Internet, (5) PowerPoint presentations, (6) spreadsheet, and (7) databases. On the other hand, more recently Talja (2005, p. 21) introduced a social constructivist viewpoint of "computer literacy" and suggests a more dialectical social constructs. In this study, computer 
competency is defined as an individual's knowledge and ability with computers. This knowledge enables an individual to use computers, software applications, databases, and other technologies to achieve a wide variety of academic, work-related, and personal goals, including a successful learning experience in web-based courses. "Computer competency" can be an indicator of "computer literacy". In this study we use them interchangeably.

A related concept to "computer competency" is "information literacy". Information literacy is a concept well discussed in library literature, for example, by Snavely and Cooper (1997), Carbo (1997), Behrens (1994), Kuhlthau (1987), McClure (1994), Bawden (2001), and Eisenberg, Lowe, \& Spitzer (2004). Information literacy is a set of abilities requiring individuals to "recognize when information is needed and have the ability to locate, evaluate, and use effectively the needed information" (American Library Association, 1989). It is believed that the two concepts are related but information literacy has broader implications for the individual, the educational system, and society.

A few studies explored the effects of computer competency to web-based distance learning. Jiang (1999) found students' previous computer competency was not a statistical significant factor in predicting students' perceived learning, but it has significant correlation with student-student communication $(p=.01)$, learning styles $(p=.03)$ and time on learning $(p=.03)$. His sample was 287 web-based students from State University of New York Learning Network. Yu, Kim, and Roh (2001) found students' perceived need of web use, technical training they had received, perceived usefulness of the web, and their computer and web competencies had positive direct effects on their web use in distance learning.

\section{Method}

This study surveyed the effects of students' computer competency to their perception of enjoyment level and difficulty level. Two research questions were explored:

1. How can a student's perception of enjoyment level with the course be affected by different individual levels of computer competency?

2. How can a student's perception of difficulty level with the course be affected by different individual levels of computer competency?

Accordingly, two null hypotheses are:
$\mathrm{HO}(1)$ : There is no difference in Enjoyment Level when the subjects differ with regard to computer competency.

$\mathrm{HO}(2)$ : There is no difference in Difficulty Level when the subjects differ with regard to computer competency.

In this study, computer competency was measured by Computer Skill and Use Assessment, which was developed by the researcher. The survey was adapted from the Information Technology Knowledge and Skills Diagnostic Tool (http://www.unt.edu/slis/apppacket/ITKS/ITKSas sess.htm), by the School of Library and Information Sciences (SLIS) at the University of North Texas. It is a technology skill self-assessment package for entering graduate students to evaluate their computer competency. ITKS is a web-based self-assessment with 197 questions. It has seven sections: Basic Computer Knowledge and Skills, Word Processing, Spreadsheet, Database, Presentation, Internet, and web Development. Enjoyment level and difficult level were assessed by the Student Satisfaction Survey. The Student Satisfaction Survey consisted of 5 items with a semantic-differential scale of 1 to 7 . The researcher chose the items for the instrument from studies by Rumpradit (1999), and Osborn (2000). Both surveys were validated in previous studies (Du, 2004; Simpson \& Du, 2004). Participants were entering graduate students in library and information science from a mid-southwestern state university in the States.

\section{Findings}

In total, 301 subjects participated in the Computer Skill and Use Assessment. Among them 237 students completed the Student Satisfaction Survey. Participants in this study were graduate students enrolled in web-based distance learning courses at a mid-southwestern state university in the United States from year 2001 to 2003. The subjects were $100 \%$ online students; they came to campus for software training because they had never taken a WebCT course. The subjects were essentially homogenous in age, gender, and knowledge level. Fourteen of them were male, the rest of them were females. Average age of the students was between 35 and 40 . Over $50 \%$ of them were school librarians or schoolteachers working toward their master's or school library certification. They all enrolled as regular master's students. Eighty percent of all enrolled students participated in the study. The courses they took were taught $100 \%$ online. 
Table 1: Descriptive Statistics of Computer Competency Items

\begin{tabular}{lcrrr} 
Item Name & Mean & \multicolumn{1}{c}{ SD } & Skewness & Kurtosis \\
\hline Q1_FILE & 6.14 & 1.04 & -1.29 & 1.34 \\
Q2_WORD & 6.62 & .70 & -1.97 & 4.11 \\
Q3_SPREAD & 5.23 & 1.45 & -.54 & -.38 \\
Q4_CUT & 6.54 & 1.05 & -3.37 & 13.72 \\
Q5_PPT & 5.14 & 1.66 & -.78 & -.13 \\
Q6_EMAIL & 6.67 & .72 & -3.36 & 17.52 \\
Q7_INTER & 6.22 & 1.03 & -1.99 & 6.37 \\
Q8_LIST & 4.51 & 1.81 & -.45 & -.64 \\
Q9_ACCESS & 2.05 & 1.42 & 1.26 & .58 \\
Q10_HTML & 2.88 & 1.82 & .61 & -.75 \\
CC $^{*}$ & 5.2 & .80 & -.66 & 1.15
\end{tabular}

Note. CC (Computer Competency) stands for average of all ten items. $1=$ least alike, $7=$ most alike

\section{Computer Competency}

Table 1 illustrates the descriptive statistics for the question items. Each item has a semanticdifferential scale, ranging from 1 to 7 . One indicates the lowest proficiency and 7 stands for the highest proficiency. The researcher expected the mean scores of the items to be between 4 and 5. From Table 1, the author found students in this sample rated themselves fairly high at basic computer skills, such as Q1 (Open/Run files and Programs, mean score $=6.14$ ), Q2 (MS Word, mean score $=6.62$ ), Q3 (Spreadsheet, mean score $=5.23$ ), Q4 (Cut and Paste, mean score $=6.54$ ), and Q6 (Using Email, mean score $=6.67$ ). Students were not familiar with computer languages, such as Q9 (Access Database Language, mean score $=2.25)$, and $\mathrm{Q} 10$ $(\mathrm{HTML}$, mean score $=2.88)$.
Several reasons may have contributed to the distribution of the current data. Firstly, students may have a tendency to rate themselves higher if they are familiar with some skills. That might yield negatively skewed scores in question items 1 to 6. Secondly, this ALA accredited library program expects that entering students have adequate skills in basic computer operation and can complete basic academic works, such as compiling homework using a word-processor. The students are supposed to pass the ITKS self-test when they apply for this program. There is a possibility that students who failed to pass the ITKS self-test but claimed to pass it were still allowed to enroll in the program. Thus, the scores of computer competency tend to be higher than expected.

Table 2: Satisfaction Measurement Variables

\begin{tabular}{lrrcc}
\hline Name & Mean & SD & Skewness & Kurtosis \\
Enjoyment Level & 5.48 & 1.39 & -.88 & .21 \\
Performance Satisfaction & 6.00 & 1.21 & -1.55 & 2.7 \\
Difficulty Level & 4.90 & 1.40 & -.71 & .29 \\
Grade Expectation & 6.83 & .42 & -2.18 & 4.04 \\
Retention Tendency & 6.23 & 1.48 & -2.05 & 3.41 \\
Satisfaction Level* $^{*}$ & 5.89 & .79 & -1.14 & .90
\end{tabular}

Note. ${ }^{*}$ Satisfaction Level is the average of all five items $(N=237)$. 


\section{Student Satisfaction}

As mentioned before, the researcher expected the mean scores of each items to be distributed around 4 to 5 with a bell-shape curve. Table 2 indicates a leptokurtic and negative skewed distribution of both Grade Expectation (Q4) and Retention Tendency (Q5), with Kurtosis more than 1 and Skewness less than -1 . The data shows that most of the students expected an "A", rather than a bell shape distribution, possibly around "B", as suggested by statistical theories. This distribution likely occurred because graduate students are expected to get at least a "B" or better. Graduate students in the sample also had a strong tendency toward retention, meaning that these students had a strong motivation to stay in this ALA accredited library program. This University has one of only three ALA accredited programs in the State of Texas. The Satisfaction Level score, or the average of mean scores of all five items, reflected a normal distribution of the sample.

\section{Correlation}

Since the dependent variable, computer competency, yields continuous scores, multiple regression analysis was applied to test the significance of correlation between computer competency and student satisfaction level. The author conducted five individual regression analyses on each question in the student satisfaction survey and found statistical significance in two Student Satisfaction items: Enjoyment Level (answers to question 1 of Student Satisfaction Survey as the dependent variable) and Difficulty Level (answers to question 3 of Student Satisfaction Survey as the dependent variable). The results are listed in the next two tables.

The next table indicated that there was a statistically significant correlation between computer competency and students' Enjoyment Level. The correlation coefficient, or $\beta$ weight, is .164 ( $p=$ 0.011). That means that computer competency as the independent variable may predict students' Enjoyment Level on web-based courses, with a correlation coefficient of .16 .

Table 3: ANOVA for Enjoyment Level

\begin{tabular}{lllllll}
\multicolumn{2}{l}{ Source Sum of Squares } & df & MS & $F$ & $p$ & $\beta$ \\
\hline Regression & 12.64 & 1 & 12.64 & 6.61 & .011 & .164 \\
Residual & 457.15 & 239 & 1.913 & & & \\
Total & 469.79 & 240 & & & &
\end{tabular}

Note: Dependent Variable: Enjoyment Level. Independent Variable: Computer

From the table below, we can conclude that there was a statistically significant correlation between computer competency and students' Difficulty Level (see Table 4 ). The $\beta$ value is $.205(p=0.001)$. That indicates that computer competency as the independent variable may predict students' impression of difficulty level of web-based courses, with a correlation coefficient of 205 .

Table 4: ANOVA Report for Difficulty Level

\begin{tabular}{lllllll}
\hline Source Sum of Squares & $\mathrm{df}$ & $\mathrm{MS}$ & $\mathrm{F}$ & $\mathrm{p}$ & $\beta$ \\
Regression & 20.27 & 1 & 20.27 & 0.49 & .001 & .205 \\
Residual & 461.99 & 239 & 1.93 & & & \\
Total & 482.27 & 240 & & & &
\end{tabular}

Note: Predictors: Dependent Variable: Difficulty Level. Independent Variable: Computer competency

There were no significant correlations between computer competency and Performance Satisfaction $(r=.052, p=.421)$, Grade Expectation $(r$ $=.034, p=.599)$, and Retention Tendency $(r=$
$.080 ; p=.217)$. There was no significant correlation between computer competency and the average of all five items $(r=.118 ; p=0.069>$ $0.05)$. Even though the correlation is not statisti- 
cally significant, the p-value is fairly close to .05 . The correlation coefficient $(\beta)$ implies there might be a significant result if the sample size were larger. The researcher believes there might be some practical significance in enhancing students' computer competency in web-based distance learning. However, we need more studies to investigate that assertion.

\section{Conclusion and Implications}

Different student computer competency levels impact students' perception of Enjoyment Level and Difficulty Level. Students feel web-based courses are easier if they have enough computer background. It is notable that a significant relationship between learning style and enjoyment level was found in previous studies (Simpson \& Du, 2004). The results of this study suggest additional factors that impact student enjoyment level in distance learning.

The findings of this study are valuable to education libraries. Understanding the effects of computer competency may help faculty to deliver learning materials more effectively online. Students in education or school library programs with higher level of computer competency are likely to be more satisfied with distance learning. Such students will be more creative with pedagogical innovation, such as utilizing Internet resources, using databases, and creating digital media in teaching and learning. Those enhanced skills may help them to achieve a wide variety of academic, work-related, and personal goals.

To better serve distant students and enhance student retention, we suggest technology support in distance education programs. Our results are consistent with findings from previous studies (Yu et al., 2001) suggesting that technology support should be provided to learners in order to facilitate the participation of web-based learning.

Students without adequate technology background should be given tutorials or training sessions to help them adjust to the online environment. Distance learning programs in libraries should provide onsite training sessions to enhance computer competency for students without enough prior knowledge of computers. In addition, distance programs might consider deploying budget in supporting students and answer students' technical questions in real-time via telephone, instant messaging, video conference, et al (Lowe \& Malinski, 2000).

The researcher found no statistically significant relationship between computer competency and pooled score of student satisfaction from all five question items. He sampled students from different majors and from different online classes. Different course types may yield a significant level of "within group variance" and thus yielded non-significant results. The researcher believes with a larger sample size significant results may be found. Computer competency may not the only factor predicting students' success in webbased distance learning. Further studies are needed to explore the interaction of computer competency and different course delivering platforms, such as GUI-based (such as WebCT) vs. text-based (Blackboard) systems.

\section{References}

American Library Association (1989). Presidential Committee on Information Literacy. Final Report. Chicago: ALA. Retrieved February 3, 2005, from: http://www.ala.org/ala/acrl/ acrlpubs/whitepapers/presidential.htm

Association for Library and Information Science Education. (1999). Educating Library and Information Science Professionals for a New Century: The KALIPER Report. Oak Ridge, TN: ALISE. Retrieved February 2, 2005, from: http://www.alise.org/publications/ kaliper.pdf

Association for Library and Information Science Education (2003). 2003 Statistical Report. Oak Ridge, TN: ALISE. Retrieved February 2, 2005, from: http://ils.unc.edu/ALISE/2003/ Curric/Curriculum01.htm

Bawden, D. (2001). Information and Digital Literacies: A Review of Concepts. Journal of Documentation, 57(2), 218-259.

Behrens, S.J. (1994). A Conceptual Analysis and Historical Overview of Information Literacy. College and Research Libraries, 55(4), 309-322.

Besser, H. (1996). Issues and Challenges for the Distance Independent Environment. Journal of the American Society for Information Science, 47(11), 817-820.

Carbo, T. (1997). Mediacy: Knowledge and Skills to Navigate the Information Super Highway. Proceedings of the Infoethics Conference, Monte Carlo, 10-12 March 1997. Paris: Unesco. 
Diekhoff, G. M. (1983). Relationship Judgments in the Evaluation of Structural Understanding. Journal of Educational Psychology, 75, 227-233.

$\mathrm{Du}, \mathrm{Y}$. (2004). Exploring the Difference between "Concrete" and "Abstract": Learning Styles in LIS Distance Education. Journal for Distance Education in Library and Information Services, 1(3), 51-64.

Eisenberg, M. E., Lowe, C. A., and Spitzer, K. L. (2004). Information Literacy: Essential Skills for the Information Age. Westport, CT: Libraries Unlimited

Frey, B. A., Alman, S. W., Barron, D., \& Steffens A. (2004). Student Satisfaction with the Online MLIS Program at the University of Pittsburgh. Journal of Education for Library and Information Science, 45(2), 82-97

Holmberg, B. (1995). The Evolution of the Character and Practice of Distance Education. Open Learning, 10(2), 47-53.

Jiang, M., \& Ting E. (1999, October). A Study of Students' Perceived Learning in a Webbased Online Environment. WebNet 99 World Conference on the WWW and Internet Proceedings. Honolulu, Hawaii. (ERIC Document No. ED 448 721).

Jonassen, D. J., \& Grabowski, B. L. (1993). Handbook of Individual Differences, Learning, and Instruction. Hillsdale, NJ: Lawrence Erlbaum Associates.

Keegan, D. (1988). On Defining Distance Education. In D. Seward, D. Keegan, B. Holmberg (Eds.), Distance Education: International Perspectives. (pp. 63-65). New York: Routledge.

Kuhlthau, C. C. (1987). Information Skills for an Information Society. Syracuse, NY: ERIC Clearinghouse. (ED 297740).

McClure, C. R. (1994). Network Literacy: A Role for Libraries. Information Technology and Libraries, 13, 115-125.

Osborn, V. (2000). Identifying At-risk Students: An Assessment Instrument for Distributed courses in Higher Education. Unpublished doctoral dissertation, University of North Texas, Denton, Texas.

Osika, E. R., \& Sharp, D. P. (2002). Minimum Technical Competencies for Distance Learning Students. Journal of Research on Technology in Education, 34(3), 318-325.
Rumpradit, C. (1999). An Evaluation of the Effect of User Interface Elements and User Learning Styles on User Performance, Confidence, and Satisfaction on the World Wide Web. Unpublished doctoral dissertation, George Washington University, Washington, DC.

Sherry, A. C., Fulford, C. P., \& Zhang, S. (1998). Assessing Distance Learners' Satisfaction with Instruction: A Quantitative and a Qualitative Method. American Journal of Distance Education 12(3), 4-28.

Simonson, M. R. Maurer, M. Montag-Torardi, M.\& Whitaker M. (1987), Development of a Standardized Test of Computer Literacy and Computer Competency Index. Journal of Educational Computing Research, 3(2), 231247.

Simpson, C. \& Du, D. (2004). Effects of Learning Styles and Class Participation on Students' Enjoyment Level in Distributed Learning Environments Journal of Education for Library and Information Science, 45(2), 123-136.

Snavely, L. and Cooper, N (1997). The Information Literacy Debate. Journal of Academic Librarianship, 23(1), 9-20.

Talja, S. (2005). The Social and Discursive Construction of Computing Skills. Journal of the American Society for Information Science and Technology, 56(1), 13-22

Tobias, S. (1976). Achievement Treatment Interactions. Review of Educational Research, 46(1), 61-74.

Tobias, S. (1981). Adapting Instruction to Individual Differences among Students. Educational Psychologist, 16, 111-120.

Tobias, S. (1982). When Do Instructional Methods Make a Difference? Educational Researcher, 11(4), 4-9.

Lowe, W, \& Malinski, R. (2000). Distance Learning: Success Requires Support. Education Libraries, 24(2/3), 15-17.

Yu, B., Kim, K., \& Roh, S. (2001, June). A User Analysis for Web-based Distance Education. Paper presented at the Annual Topics on Distance Learning Conference, Hammond, Indiana (ERIC Document No. ED 455 830). Retrieved February 3, 2005, from: http://www.calumet.purdue.edu/todl/proceedi ngs/2001/2001proceedings.htm 


\section{Appendix: Computer Skill and Use Assessment}

Rate your ability to do each of the following:

(circle the appropriate number, from 1 (no knowledge/ability) to 7 (expert user))

No knowledge 12334567 Expert user

1. Find, open and run files and programs

2. Create a document using a word processor

3. Use a spreadsheet to create a document

4. Cut, copy, and paste text

5. Create a presentation document on a computer

6. Send and receive e-mail

7. Search for information on the Internet/World Wide Web

8. Subscribe and post messages to a "listserv"

9. Program a computer using a database language (such as Access, Foxpro or Oracle, etc.)

10. Create or edit a Website (using html, Java, etc.)

11. Electronically send and receive files
1234567

1234567

1234567

1234567

1234567

1234567

1234567

1234567

1234567

1234567

1234567

12. Generally, how satisfied are you with your computer ability (choose one)

O Very Dissatisfied

O Dissatisfied

O Dissatisfied with reservation

O Satisfied

O Very Satisfied

O No Basis for Judgment/ Not Applicable

Comments:

Yunfei Du is an Assistant Professor, Library and Information Science Program, at Wayne State University, Detroit. E-mail: yunfei@wayne.edu 